Int. J. Electrochem. Sci., 13 (2018) 3855 - 3873

International Journal of

ELECTROCHEMICAL

SCIENCE

www.electrochemsci.org

\title{
A Study on Gold-Silver Alloy Electrodeposition from Pyrophosphate-Cyanide Electrolyte Using Polyethylenimine- KSeCN Additives
}

\author{
Kubra Akben ${ }^{*}$, Servet Timur \\ Department of Metallurgical and Materials Engineering, Istanbul Technical University, 34469 Maslak, \\ Istanbul, Turkey \\ *E-mail: hk.akben@gmail.com
}

doi: $10.20964 / 2018.04 .07$

Received: 27 October 2017 / Accepted: 3 January 2018 / Published: 6 March 2018

This paper presents the electrodeposition of gold-silver alloys from pyrophosphate-cyanide baths in the presence of a brightener couple, polyethylenimine $(\mathrm{Mw}=600 \mathrm{~g} / \mathrm{mol}$ ) and $\mathrm{KSeCN}$. The nanocrystalline (X-ray diffraction) single phase electrodeposits with gold content ranging from 69 to $78 \mathrm{wt} \%$ (energy dispersive spectroscopy) are obtained galvanostatically. The influence of the polyethylenimine and $\mathrm{KSeCN}$ on the reduction kinetics of gold-silver alloy electrodeposition and on the mechanism of the electrodeposition process was studied by cyclic voltammetry and chronoamperometry. We observe that polyethylenimine polarizes the alloy deposition to high cathodic potentials and enhances the gold content from ca. 45 to $75 \mathrm{wt} \%$ in a current density range from 5 to 10 $\mathrm{mA} . \mathrm{cm}^{-2}$ with the support of $\mathrm{KSeCN}$ additive. Moreover, the alloy electrodeposition is found to proceed by a progressive nucleation and diffusion-controlled 3D growth mechanism with the addition of the brightener couple. We also discuss the morphological (scanning electron microscopy) and color changes in the presence of additives. Bright and coherent gold-silver alloy deposits are produced using the synergistic effects of polyethylenimine and $\mathrm{KSeCN}$.

Keywords: Electrodeposition, Gold alloy, Silver, Brightener, Pyrophosphate-cyanide bath

\section{$\underline{\text { FULL TEXT }}$}

(C) 2018 The Authors. Published by ESG (www.electrochemsci.org). This article is an open access article distributed under the terms and conditions of the Creative Commons Attribution license (http://creativecommons.org/licenses/by/4.0/). 